\title{
SOROPREVALÊNCIA PARA LEPTOSPIROSE EM CÃES DE CURITIBA, PARANÁ
}

\section{Soroprevalence for leptospirosis in dogs from Curitiba, Paraná}

\section{Resumo}

Investigou-se a prevalência de leptospirose em cães da cidade de Curitiba, Paraná. Foram examinadas 399 amostras de soro sangüíneo, no Laboratório de Análises Clínicas Veterinárias "Veterinária Preventiva", no perío do de 01 de outubro a 30 de setembro de 2005, de cães de ambos os sexos e de diferentes raças e idades. O diagnóstico de leptospirose foi feito pela técnica de somaglutinação microscópica, testando-se nove sorovares. Das 399 amostras, 114 (28,57\%) foram reagentes para os seguintes sorovares: copenhageni $(86,84 \%)$, canicola $(9,65 \%)$ e icteroha emorrhagiae (2,63\%). A única infecção mista foi observada devido aos sorovares copenhageni e bratislava $(0,87 \%)$.

Palavras-chave: Cães; Soroprevalência; Leptospirose; Leptospira interrogans.

\section{Abstract}

The prevalence of leptospirosis was investigated in dogs from Curitiba, PR. Tree hundred ninety nine (399) blood samples were examined, in the Clinical Analysis Laboratory "Veterinária Preventiva”, from October to September 2005. Both sex and different ages and breeds dogs were used. The diagnostic method used was the Microscopic Agglutination Test (MAT), using nine different sorovars. Considering the sample, 114 (28.57\%) were reactive with occurrence of the copen hageni (86.84\%), canicola (9.65\%) and icterohaemorrhagiae (2.63\%). Mixed infection was observed with copenhageni and bratislava $(0.87 \%)$ sorovars.

Keywords: Dogs; Soroprevalence; Leptospirosis; Leptospira interrogans.

Médicos(as) Veterinários(as), Laboratório de Análises Clínicas Veterinárias “Veterinária Preventiva” - Curitiba-PR

2 Médico Veterinário, Ph.D., Professor do Departamento de Medicina Veterinária da Universidade Federal do Paraná, Curitiba-PR, R. São Pedro, 470, CEP 80035-020 


\section{Introdução}

A leptospirose é uma doença bacteriana infectocontagiosa, aguda e potencialmente grave, causada pela Leptospira interrogans. É uma zoonose cosmopolita, que pode ocorrer tanto na forma esporádica quanto endêmica (FAINE et al., 1999).

Os surtos ocorrem devido à exposição à água contaminada com urina ou tecidos provenientes de animais infectados (VASCONCELLOS, 1993). No Brasil, assim como em outros países em desenvolvimento, a maioria das infecções ocorre pelo contato com águas de enchentes contaminadas por urina de ratos. Nesses países, a ineficácia ou inexistência de rede de esgoto e drenagem de águas pluviais e a coleta de lixo inadequada são condições favoráveis à alta endemicidade e às epidemias de leptospirose (SECRETARIA DE AÇÕES BÁSICAS DE SAÚDE, 1997).

A infecção pela Leptospira interrogans também pode ocorrer pela ingestão de água e alimentos contaminados com urina de ratos ou pelo contato com urina de animais domésticos, mesmo quando esses foram vacinados, pois podem tornar-se portadores assintomáticos da bactéria (VASCONCELLOS, 1993).

A principal fonte de infecção da leptospirose humana, no ambiente urbano, é o cão, pois vivem em contato direto com seres humanos e podem apresentar leptospiras vivas na urina durante meses, mesmo sem apresentar nenhum sinal clínico (FAINE et al., 1999). Os sinais clínicos da leptospirose canina dependem de fatores como idade, estado imunológico e virulência do sorovar; as formas menos graves evoluem para febre, anorexia, vômito, desidratação e apatia; a forma crônica não é aparente, levando à insuficiência renal crônica (SANTIM et al., 2006).

O Brasil apresentou 4128 casos de leptospirose humana no ano 2000; a maior parte deles no estado de São Paulo, segundo dados divulgados pela Fundação Nacional de Saúde (FUNASA, 1996). Apenas os casos mais graves (ictéricos) são, geralmente, diagnosticados e, eventualmente, notificados. A leptospirose não ictérica é, freqüentemente, confundida com outras doenças (gripe, por exemplo) e por isso não há procura de assistência médica. A notificação, portanto, representa apenas uma pequena parcela (provavelmente 10\%) do número real de casos no Brasil.
Vários inquéritos sorológicos realizados em cães no Brasil mostram a variabilidade na distribuição de sorovares de Leptospira interrogans em diferentes regiões. Em Pelotas (RS), Furtado et al. (1997) examinaram 260 cães com prevalência de $28,9 \%$ e destaque para os sorovares canicola e icterohaemorrhagiae. Também em Pelotas, Avila et al. (1998) encontraram 34,8\% de soros positivos em 425 cães, com predomínio dos sorovares canicola, icterohaemorrhagiae e copenhageni; e Jouglard; Brod (2000) encontraram $2,7 \%$ de positividade em 489 cães com destaque para os sorovares icterohaemorrhagiae, australis, copenhageni, pyrogenes, sentot e canicola. Alves et al. (2000) encontraram 20\% de soros positivos em 114 cães da cidade de Patos (PB), com destaque para os sorovares autumnalis, butembo, grippotyphosa e australis. Em Santana de Parnaíba (SP), Mascolli et al. (2002) examinaram 410 amostras de soro de cães e encontraram 15\% de soros positivos com predomínio dos sorovares copenhageni, canicola e hardjo. Em Campina Grande (PB), Batista et al. (2005) encontraram 21,4\% de prevalência (em 285 amostras de cães), com maior freqüência dos sorovares autumnalis, copenhageni e canicola.

O objetivo deste trabalho foi determinar a soro prevalência de leptospirose em cães do município de Curitiba, estado do Paraná.

\section{Material e métodos}

Foram examinadas 399 amostras de soro de cães, recebidas pelo Laboratório de Análises Clínicas Veterinárias “Veterinária Preventiva”, CuritibaPR, no período de 01 de outubro a 30 de setembro de 2005. As amostras foram mantidas sob refrigeração e analisadas no mesmo dia da colheita.

As amostras foram obtidas de cães domiciliados, de ambos os sexos e de diferentes raças e idades, de diversas áreas da cidade de Curitiba, estado do Paraná.

O diagnóstico sorológico de leptospirose foi realizado pela técnica de soroaglutinação microscópica (GALTON et al., 1965), com titulação sorológica de 1:25 a 1:400, onde foram testados os seguintes sorovares: canicola, grippotyphosa, icteroha emorrhagiae, pomona, copenhageni, wolffi, bratislava, hebdomadis e hardjoprajitno. 


\section{Resultados}

Das 399 amostras de soro, 114 (28,57\%) foram reagentes. O sorovar mais freqüente foi copenhageni $(86,84 \%)$. Também foram observados soros reagentes para os sorovares canicola $(9,65 \%)$ e icteroha emorrhagiae (2,63\%).
A Tabela 1 apresenta a quantidade e a porcentagem dos sorovares encontrados e seus respectivos títulos.

A única infecção mista ocorreu devido à presença dos sorovares bratislava e copenhageni (1,36\%), ambos na titulação de 1:25.

TABELA 1 - Número e porcentagem de sorovares de Leptospira interrogans encontrados e seus respectivos títulos. Laboratório de Análises Clínicas Veterinárias "Veterinária Preventiva"1, Curitiba-PR, no período de 01 de outubro a 30 de setembro de 2005.

Table 1 - Number and percentage of sorovars of joined Leptospira interrogans and its respective headings. Veterinary Clinical Analyses Laboratory “Veterinária Preventiva”, Curitiba-PR, from October 01 to September 31 of 2005.

\begin{tabular}{|l|l|l|l|}
\hline Sorovar & Titulação & $\begin{array}{l}\text { Número de amostras } \\
\text { positivas }\end{array}$ & $\mathbf{\%}$ \\
\hline copenhageni & $1: 25$ & 20 & 17,54 \\
& $1: 50$ & 27 & 23,68 \\
& $1: 100$ & 23 & 20,18 \\
& $1: 200$ & 18 & 15,79 \\
& $1: 400$ & 11 & 9,65 \\
Subtotal & & 99 & 86,84 \\
canicola & $1: 25$ & 5 & 4,39 \\
& $1: 50$ & 4 & 3,51 \\
Subtotal & $1: 200$ & 2 & 1,75 \\
icterohaemorrhagiae & $1: 25$ & 11 & 9,65 \\
& $1: 50$ & 4 & 4,39 \\
Subtotal & $1: 100$ & 2 & 3,51 \\
bratislava + copenhageni & $1: 25$ & 3 & 1,75 \\
Subtotal & & 1 & 2,63 \\
\hline TOTAL DE AMOSTRAS & & 1 & 0,87 \\
& & 114 & 0,87 \\
\hline
\end{tabular}

1 Veterinária Preventiva - Rua São Pedro, 470 Cabral - Fone: (41)3352-4480 Fax: (41)3353-1160 CEP 80035-020 - Curitiba-PR. E-mail: veterinariapreventiva@veterinariapreventiva.com.br

\section{Conclusões}

A prevalência do sorovar copenhageni (86,84\% em diferentes diluições) aponta a importância da população de roedores na transmissão da leptospirose e reforça a necessidade de programas de controles de roedores (desratização, por exemplo), inclusão de modificações ambientais como medidas preventivas (anti-ratização) e a educação em saúde. Os ratos e as ratazanas, considerados os portadores universais das leptospiras, são um dos principais responsáveis pela transmissão da doença. 
O sorovar canicola, que foi o segundo mais prevalente (9,65\% em diferentes diluições), indica que o cão é uma importante fonte de infecção para 0 homem. O cão é o principal hospedeiro desse sorovar, que apresenta adaptação ao tecido renal canino, podendo ser eliminado por um longo período.

Os sorovares isolados de pacientes humanos hospitalizados com leptospirose no estado de São Paulo, entre 1986 e 1989, foram copenhageni $(77,8 \%)$ e canicola $(11,1 \%)$ (SAKATA et al., 1992). Esses resultados convergem com o presente estudo e sugerem que os sorovares que circulam entre a população humana e a de cães são os mesmos. Entretanto, a maioria dos levantamentos realizados em cães, no Brasil e no exterior, indica predomínio dos sorovares icterohaemorrhagiae e canicola em vez do copenhageni (SCANZIANI et al., 1994).

Santim et al. (2006) encontraram aglutininas anti-Leptospira em maior proporção contra os sorovares copenhageni e icterohaemorrhagiae, tanto em cães sadios quanto em cães com suspeita clínica de leptospirose, no município de Porto Alegre, RS.

Reação positiva também foi observada, no presente estudo, para icterohaemorrhagiae $(2,63 \%)$. A única infecção mista foi observada para bratislava e copenhageni $(0,87 \%)$. O sorovar bratislava é comum em cães de fazenda, provavelmente por isso um pequeno número de amostras foi reativa $(0,87 \%)$, já que a maioria dos soros eram provenientes de cães domiciliados.

A presença marcante do sorovar copenhageni causa preocupação, visto que não existe imunidade cruzada entre os diferentes sorovares, e as vacinas veterinánias disponíveis são compostas, basicamente, pelos sorovares canicola e icterohaemorrhagiae. Isso reforça a importância de pesquisas para 0 desenvolvimento de novas vacinas contra leptospirose, visando uma maior efetividade e imunidade mais duradoura.

\section{Referências}

ALVES, C. J.; ANDRADE, J. S. L; VASCONCELLOS, S. A. Avaliação dosníveis de aglutininas anti-lepstospiras em cães no município de Patos-PB, Brasil. Rev. Bras. Ciênc. Vet. v. 7, p. 17-21, 2000.

ÁVILA, M. O.; FURTADO, L. R. I.; TEIXEIRA, M. M. Aglutininas anti-lepstospira em cães na área de influência no centro de Controle de Zoonoses,
Pelotas, RS, Brasil, no ano de 1995. Ciênc. Rural, v. 28, p. 107-110, 1998.

BATISTA, C. S. A. et al. Soroprevalência e fatores de risco para a leptospirose em cães de Campina Grande, Paraíba. Arq. Bras. Med. Vet. Zootec. v. 57, supl.2, 2005.

FAINE, S.; ADLER, B.; BOLIN, C. Leptospira and leptospirosis. 3. ed. Melboume: MediSei, 1999.

FUNASA - Fundação Nacional de Saúde. Informe Epidemiológico do SUS. Brasília, 1996.

FURTADO, LR.I.; AVILA, M.O.; FEHLBERG, M.F.B.. Prevalência eavaliação de fatores de risco à leptospirose canina, no município de Pelotas - RS. Arq. Inst. Biol. v. 64, p. 57-61, 1997.

GALTON, M. M.; SULZER, C. R; SANTA ROSA, C. A. Aplication of a microtecnique to the aglutination test for leptospiral antibodies. Appl. Microbiol. v. 13, p. 81-85, 1965.

JOUGLARD, S. D. D.; BROD, C. S. Leptospirose em cães: prevalência e fatores de risco no meio rural do município de Pelotas, RS. Arq. Inst. Biol.v. 67, p. 181185, 2000.

MASCOLL, R; PINHEIRO, S. R.; VASCONCELLOS, S. A. Inquérito somológico para leptospirose em cães do Município de Santana de Pamaíba, São Paulo, utilizando a campanha de vacinação anti-rábica do ano de 1999. Arq. Inst. Biol. v. 40, p. 430-431, 1999.

SAKATA, E. E.; YASUDA, P. H.; ROMERO, E. C. Sorovares de Leptospira interrogansisoladas de casos de leptospirose humana em São Paulo, Brasil. Ver. Inst. Med. Trop. São Paulo, v. 34, p. 217-221, 1992.

SANTIM, K. etal. Pesquisa de aglutininasantiLeptospira em cães clinicamente sadios e em cães com suspeita clínica de leptospirose. Clínica Veterinária, n. 60, p. 48-52, 2006.

SCANZIANI, E; CALCATERRA, S.; TAGLABUE, S. Serologic findings in cases of acute leptospirosis in the dog. J. Small Anim. Pract. v. 35, p. 257-260, 1994.

SECRETARIA DE AÇÕES BÁSICAS DE SAÚDE. Divisão de Zoonoses. Brasília, 1997.

VASCONCELLOS, S. A. Leptospirose Animal. In: ENCONTRO NACIONALEM LEPTOSPIROSE, 3., Rio de Janeiro, 1993. Anais... Rio de Janeiro:[s. n.], 1993. p. 62-65.

Recebido em: 03/10/2005

Aprovado em: 10/10/2005 